\title{
The Action of Tetanus Toxin in Frogs
}

\author{
By K. E. K. ROWSON \\ Department of Pathology, Guy's Hospital Medical School, London, S.E. 1*
}

\begin{abstract}
SUMMARY
The development of tetanus intoxication in the frog is dependent on the environmental temperature being above about $15^{\circ}$. The incubation period and time to death become shorter as the environmental temperature is raised. Cooling below about $15^{\circ}$ prevents both the fixation of the toxin and its action after fixation but does not increase the speed at which the toxin is destroyed or excreted. The absorption of the toxin after injection into the dorsal lymph sac is not prevented by cooling. It is possible to produce local tetanus in frogs by the intramuscular injection of tetanus toxin, but the dose needed for this is very critical. In most cases either generalized tetanus develops or there are no signs of intoxication. However, local tetanus can regularly be produced when the toxin is given intramuscularly to frogs partially protected from generalized tetanus by an injection of tetanus antitoxin given via the dorsal lymph sac. The local tetanus so produced does not progress to involve the opposite limb. The muscular spasm is abolished by cutting the motor nerve or by general anaesthesia. Tetanus toxin appears to act on the central nervous system of the frog in the same manner as in mammals. However, frog brain tissue does not neutralize tetanus toxin in low concentrations as does mammalian brain tissue, but concentrated tetanus toxoid gives immediate protection to frogs in the same way as it does in mammals.
\end{abstract}

\section{INTRODUCTION}

The action of tetanus toxin on cold blooded vertebrates has not been extensively studied, but the majority of those species on which the toxin has been tested have proved susceptible. However, the dose of toxin required to produce tetanus is much greater than for even the most resistant of mammals and susceptibility is dependent on the environmental temperature being above a certain level. Courmont \& Doyon (1893) were the first to observe that frogs became susceptible to tetanus toxin when kept at a temperature above $20^{\circ}$. Morgenroth (1900) endeavoured to analyse the mechanism of the temperature-dependent resistance of the frog to tetanus toxin. $\mathrm{He}$ inoculated frogs kept at $8^{\circ}$ with tetanus toxin and found that they remained normal unless warmed to $32^{\circ}$ when, after 2-3 days, they developed tetanus. However when, after being warmed for only $24 \mathrm{hr}$. and before signs of intoxication occurred, they were returned to the cold they remained in good health. On being warmed a second time, these frogs developed tetanus after a shorter interval than frogs similarly inoculated and warmed for the first time. Cold therefore arrests the development of tetanus even when part of the incubation process has taken place. It does not however annul the process of intoxication, because the sum of the two successive incubation periods remained the same as that of the single one which had been uninterrupted

* Present address: Department of Cancer Research, London Hospital Medical College, E. 1. 
by any cooling. The only other amphibian about which the action of tetanus toxin has been reported is the axolotl, a larval salamander of the genus Amblystoma, which Metchnikoff (1897) found to be very sensitive. Of other poikilothermic vertebrates, there is one report on the effect of tetanus toxin on fish, by Lapenta (1932) who suggested that the gold fish Carassius auratus would be very suitable for the assay of tetanus toxin. The reptiles have been a little more fully investigated. Grasset \& Zutendyk (1931), in South Africa, were able regularly to produce signs of tetanus in lizards, young crocodiles and snakes, but tortoises were only susceptible to intracerebrally injected toxin. Cowles \& Nelson (1947) used the American crested lizard and were able to produce signs of tetanus. However, Metchnikoff (1897) failed to demonstrate tetanus in the European green lizard. With all the susceptible reptiles it was found that the development of tetanus intoxication depended on the environmental temperature. At low temperatures signs of tetanus either failed to appear or the incubation period was longer than at higher temperatures.

The present investigation was undertaken to see whether tetanus toxin appears to act in frogs in the same way as in mammals, or whether in these cold-blooded partially resistant animals it has some different mode of action.

\section{METHODS}

Frogs and aquaria. The frogs used in all the following experiments were of the common British species Rana temporaria and were obtained at intervals as required from Cornwall. They were of both sexes and varied in weight between 15 and $30 \mathrm{~g}$. Galvanized iron tanks about $2 \mathrm{ft}$. square were used as aquaria. Different environmental temperatures were obtained by means of thermostatically-controlled low temperature electric immersion heaters or by placing the tanks in a refrigerated room. In most experiments control animals were kept in the same tank as the intoxicated ones. It was rare for a control frog to die from natural causes; they remained healthy over long periods at temperatures between $5^{\circ}$ and $27^{\circ}$.

Blood samples from frogs. These were obtained by exposing the heart under ether anaesthesia and puncturing the ventricle with a fine glass pipette containing $10 \mathrm{~mm} .^{3}$ heparin (Liquemin, Roche Products Ltd, 5000 i.u./ml.). The blood was centrifuged and about $\mathbf{0} \cdot 25 \mathrm{ml}$. plasma obtained per frog.

Tetanus toxin. The toxin preparation was kept as a finely ground powder in a vacuum desiccator until dissolved in sterile saline a few minutes before use. Two preparations of tetanus toxin were used. The first was some of that described by Wright, Morgan \& Wright (1950) and will be referred to as toxin A; the LD50 dose for mice, determined by the death time method of Ipsen (1941) was about $0.05 \mu \mathrm{g}$. The second preparation of tetanus toxin, toxin B, was provided by Dr Mollie Barr (The Wellcome Research Laboratories); the LD50 dose for mice was $0.005 \mu \mathrm{g}$.

Tetanus antitoxin. The antitoxin containing 1500 international units/ml. was supplied by Burroughs Wellcome and Co. Ltd.

Tetanus toxoid. A concentrated preparation of tetanus toxoid (TD $343 \mathrm{D}$ ) containing 1175 Lf doses/ml. was provided by Dr Mollie Barr. 
RESULTS

\section{Generalized tetanus in frogs}

The concentration of toxin in the blood following inoculation. In most of the following experiments the inoculations were made into the dorsal lymph sac. Thorotrast (a thorium dioxide preparation) injected by this route reaches the blood stream very rapidly and then slowly passes from the blood into the tissue fluids (Foxon \& Rowson, 1956). That tetanus toxin behaves in the same way seemed very probable but some experiments were made to confirm this and to determine the effect of different environmental temperatures on the concentration of toxin in the blood following injection into the dorsal lymph sac. As it is not possible to take samples of blood from the same frog at intervals, a group of similar frogs were each injected with $1.0 \mathrm{mg}$. tetanus toxin A in $0.5 \mathrm{ml}$. saline and bled at different times. The frogs were kept in three groups at $5^{\circ}, 15^{\circ}$ and $26^{\circ}$.

Table 1. The plasma concentration of tetanus toxin following injection into frog dorsal lymph sac

\begin{tabular}{|c|c|c|c|}
\hline \multirow{3}{*}{$\begin{array}{c}\text { Time after } \\
\text { injection } \\
\text { of } 1.0 \mathrm{mg} . \\
\text { tetanus toxin } \\
\text { (days) }\end{array}$} & \multicolumn{3}{|c|}{ Frogs kept at } \\
\hline & \multirow{2}{*}{\multicolumn{3}{|c|}{$\begin{array}{c}5^{\circ} \\
1^{\circ}\end{array}$}} \\
\hline & & & \\
\hline $0 \cdot 125$ & 一 & 560 & 625 \\
\hline 1 & $185(2)$ & 520 & 450 \\
\hline 2 & $280(2)$ & 235 & 300 \\
\hline 3 & $305(2)$ & 130 & 340 (2) \\
\hline 4 & 310 & 230 & 275 \\
\hline 5 & 295 & $150(2)$ & $\mathbf{2 5 0}$ \\
\hline 6 & 300 & - & $350(2)$ \\
\hline 8 & 150 & - & - \\
\hline 12 & - & 85 & - \\
\hline 14 & 190 & - & - \\
\hline 18 & - & 62 & - \\
\hline 19 & - & 26 & - \\
\hline 21 & 150 & - & - \\
\hline 33 & 250 & - & - \\
\hline
\end{tabular}

Values marked (2) are the average of two experiments.

Table 1 shows the amount of tetanus toxin found in the plasma of these three groups of frogs. At $15^{\circ}$ and $26^{\circ}$ the blood concentration was very high after only $3 \mathrm{hr}$. and then decreased fairly rapidly during the next 3-4 days as the toxin passed from the plasma into other tissues. At $5^{\circ}$ the concentration in the blood increased slowly during the first 3 days, to reach about the same value as that found in the other two groups at this time. The frogs at $5^{\circ}$ were lethargic, showed very little voluntary movement even when disturbed, and the lymph hearts beat at a decreased rate. Therefore it was not surprising that toxin injected into the dorsal lymph sac reached the blood stream more slowly in frogs at $5^{\circ}$ than in those at higher temperatures. Because the toxin was entering the circulation at a diminished rate in frogs at $5^{\circ}$, there was time for it to become distributed throughout the body fluids while it was being absorbed from the dorsal lymph sac, with the result that the maximum concentration in the blood found in these frogs was not so high as in those kept at $15^{\circ}$ or 
$26^{\circ}$. In the frogs at $26^{\circ}$ death occurred before the seventh day, so the toxin concentration could only be followed for 6 days. However, in the other two groups clinical tetanus did not develop and the blood toxin concentration was followed and found to decrease very slowly, especially in the frogs kept at $5^{\circ}$, where even after 33 days there was a high proportion of toxin still circulating. At $15^{\circ}$ the amount of toxin in the plasma decreased more rapidly and after 19 days had reached such a low value that the frogs could be warmed to $26^{\circ}$ without developing tetanus.

From this experiment it is clear that tetanus toxin rapidly reaches the general circulation from the dorsal lymph sac, and that although cooling slows down the rate of entry it does not prevent the toxin reaching the blood stream. The lower maximum blood toxin concentration in the frogs at $5^{\circ}$ cannot account for their insusceptibility to tetanus since the frogs at $18^{\circ}$ were also unaffected, and their blood toxin concentration was initially as high as in the group at $26^{\circ}$ which developed tetanus.

The physical signs of generalized tetanus. After the injection of tetanus toxin into the dorsal lymph sac Gumprecht (1895) found that the onset of tetanus was generalized, but Brunner (1894) reported that the onset was in the fore limbs even when the toxin was injected into a back leg. Zupnik (1905) produced ascending tetanus by an inoculation into the dorsum of the foot but Fröhlich \& Meyer (1916) were only able to obtain this effect by inoculation into the cord. In the present experiments, the injection of tetanus toxin into the dorsal lymph sac produced a generalized condition in which all four limbs were affected at the same time. In the very early stages there was only a slight limitation of movement, most easily seen in the hind legs when the frog was raised from the water by a hand placed under the forepart of the body. A normal frog easily climbs onto the hand, whereas a frog with early tetanus cannot bring its hind legs far enough forward; there was a limitation of flexion. Soon the fore legs became fixed across the front of the chest (Pl. 1, fig. 1) and the frog could swim, able to make ever decreasing movements with his hind legs, which hung down in the water; eventually the hind legs became rigidly extended (Pl. 1, fig. 2) and the frog floated helplessly on the water. Reflex spasms occurred when the condition was well developed but were only obvious in the hind legs. The lymph hearts did not seem to be affected by tetanus toxin and continued to beat normally up to the end. It is in fact only by their continued beating in the final stages that the presence of life can be discerned.

The rate at which the intoxication progressed depended on the body temperature. At $26^{\circ}$ death often occurred within $24 \mathrm{hr}$. of the first signs of tetanus, whereas at $18^{\circ}$ the signs slowly progressed for 3 to 4 days and a frog might remain completely unable to move for a day or two before death. However, although cooling slowed its rate of progress it did not annul the process.

The relationship of dose of toxin and body temperature to time of death. Table 2 shows the median death time for groups of frogs, all kept at $26^{\circ}$ but injected with different doses of tetanus toxin $\mathbf{A}$ into the dorsal lymph sac. The death time rapidly increased when the dose of toxin was below $0.5 \mathrm{mg}$. The figures in Table 2 give a curve very similar to that obtained by Ipsen (1941) with mice, except that the LD 50 dose for a frog is very much larger and must be in the region of $150 \mu \mathrm{g}$. as compared with $0.05 \mu \mathrm{g}$. for a mouse. Therefore at $26^{\circ}$ the frog is about 3000 times as resistant as the mouse, but in the frog the lethal dose differs very much with the body temperature.

The effect of body temperature on the death time can be seen in Table 3, where the 
median death time is shown for groups of frogs kept at different environmental temperatures but each injected with $0.5 \mathrm{mg}$. tetanus toxin $\mathbf{A}$ into the dorsal lymph sac. Below $20^{\circ}$ the death time rapidly increased; at about $18^{\circ}$ the frogs appeared to become completely resistant to the action of tetanus toxin in that dosage. Probably if the dose of toxin were increased, tetanus would develop in the frogs kept at a slightly lower temperature than $20^{\circ}$, but it is clear that cooling had a pronounced protective action. This was particularly remarkable in view of the fact that the frogs remained

Table 2. The relationship between toxin dosage and death time at $26^{\circ}$

Groups of four frogs were used at each dose value. Toxin injected into dorsal lymph sac.

$\begin{array}{cc}\begin{array}{c}\text { Dose of toxin } \\ \text { (mg.) }\end{array} & \begin{array}{c}\text { Median } \\ \text { death time } \\ \text { (days) }\end{array} \\ 2 & 6.5 \\ 1 & 7 \\ 0.5 & 8.5 \\ 0.25 & 16\end{array}$

Table 3. The relationship between body temperature and death time

Groups of 10 frogs were used at each temperature. Tetanus toxin A (0.5 mg.) injected in dorsal lymph sac.

\begin{tabular}{|c|c|}
\hline $\begin{array}{c}\text { Temperature } \\
\left({ }^{\circ} \mathrm{C} .\right)\end{array}$ & $\begin{array}{c}\text { Median } \\
\text { death times } \\
\text { (days) }\end{array}$ \\
\hline 28 & $3 \cdot 0$ \\
\hline 23 & $7 \cdot 5$ \\
\hline 18 & Over 21 \\
\hline
\end{tabular}

Table 4. The effect of antitoxin on the death time of frogs at $27^{\circ}$ when given at different intervals after a standard dose of toxin

Groups of 6 frogs were used. Dose of antitoxin : $0.2 \mathrm{ml}$. 300 international units. Dose of toxin : $0.5 \mathrm{mg}$. tetanus toxin $\mathrm{A}$.

$\begin{array}{cc}\begin{array}{c}\text { Interval between } \\ \text { toxin and antitoxin } \\ (\mathrm{hr} .)\end{array} & \begin{array}{c}\text { Median } \\ \text { death time } \\ \text { (days) }\end{array} \\ \mathbf{2 4} & \text { Survived } \\ 48 & 8 \\ 72 & 4.5\end{array}$

quite active at temperatures down to $14^{\circ}$ and only showed slight lethargy at $10^{\circ}$. The protective effect of a decrease in body temperature does not seem to be due to an alteration in the absorption or fate of the toxin in the body. Therefore the effect of environmental temperature on the fixation of toxin to, and action on, susceptible structures was studied.

Body temperature and the fixation of tetanus toxin. When tetanus toxin has passed to its site of action in the central nervous system and the development of tetanus cannot be prevented by the injection of antitoxin, it is said to have become fixed. In frogs living at $27^{\circ}$ a lethal dose of toxin was fixed $48 \mathrm{hr}$. after injection as shown in Table 4. 
This shows the results of an experiment in which three groups of frogs received a gross immunological excess of tetanus antitoxin $(0.2 \mathrm{ml}$.) at different intervals after the injection of a lethal dose of tetanus toxin (0.5 mg. toxin A). By the end of $48 \mathrm{hr}$. although a lethal dose of tetanus toxin had been fixed the antitoxin was able to prolong the frog's life. Presumably this was because further toxin would have been fixed during the next $24 \mathrm{hr}$. After 3 days antitoxin has no effect on the death time. In contrast to the rapid fixation of tetanus toxin which took place at $27^{\circ}$ was the complete failure of fixation at temperatures below about $18^{\circ}$. Frogs living at $15^{\circ}$ were completely protected by antitoxin given a week or more after the inoculation of tetanus toxin, showing that fixation of a lethal dose had not occurred.

Table 5. The effect of cooling from $26^{\circ}$ to $18^{\circ}$ for different periods beginning $48 \mathrm{hr}$. after the injection of tetanus toxin.

Dose of tetanus toxin A: $1.0 \mathrm{mg}$.

Number of
frogs
7
7
6
6

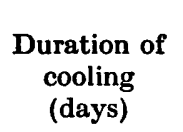

Not cooled

$\mathbf{3}$

6

$\mathbf{9}$
Increase in median death time due to cooling (days)

$$
\begin{aligned}
& \overline{3} \\
& 5 \\
& 7 \cdot 5
\end{aligned}
$$

Table 6. The effect of cooling from $26^{\circ}$ to $5^{\circ}$ for different periods beginning $48 \mathrm{hr}$. after the injection of tetanus toxin

Dose of tetanus toxin A: 1.0 mg.

$\begin{array}{cccc}\begin{array}{c}\text { Number of } \\ \text { frogs }\end{array} & \begin{array}{c}\text { Duration of } \\ \text { cooling } \\ \text { (days) }\end{array} & \begin{array}{c}\text { Median } \\ \text { death time } \\ \text { (days) }\end{array} & \begin{array}{c}\text { Increase in median } \\ \text { death time due to } \\ \text { cooling } \\ \text { (days) }\end{array} \\ 6 & \text { Not cooled } & 7 & - \\ 6 & 6 & 14 & 7 \\ 6 & 9 & 16.5 & 9 \cdot 5\end{array}$

Body temperature and the injurious action of tetanus toxin after fixation. From the observations recorded above it can be seen that cooling prevented the development of tetanus in the frogs and that the fixation of toxin was delayed and might not take place to the extent of a lethal dose. The action of toxin after fixation also seemed to be inhibited; this was shown by experiments in which groups of frogs were cooled after toxin had been allowed time to become fixed. All the frogs were inoculated with tetanus toxin (1.0 mg. toxin A) and kept at $26^{\circ}$ for $48 \mathrm{hr}$. in order to ensure that a lethal dose of toxin had become fixed. In the first experiment, batches of these frogs were then transferred to a tank at $18^{\circ}$ for different periods of time, at the end of which they were returned to the tank at $26^{\circ}$. Table 5 shows the length of time each group spent in the tank at $18^{\circ}$ and their median death time. In column 4 of Table 5 the increase in the survival time over that of the control frogs is recorded, and it is clear that although the death time had been much prolonged by the cooling the increase was not quite equal to the duration of cooling. Therefore it appears that at $18^{\circ}$ the 
toxin was able to act, but only very slowly. In the second experiment frogs were cooled to $5^{\circ}$ instead of to $18^{\circ}$. This more severe chilling prevented completely the injurious activity of the toxin (Table 6). The death time appeared to have been increased more than the duration of cooling (Table 6, column 4). If the action of the toxin was in fact annulled at this low temperature the increase in death time after cooling for 9 days ought to have been more than after 6 days, but it was not.

\section{The effect of tetanus toxin given by different routes}

The intramuscular route compared with inoculation into the dorsal lymph sac. It has been shown by several workers (Fildes, 1931, p. 308) that in mammals the minimal lethal dose of tetanus toxin by intravenous injection is about 5 times greater than the minimal lethal dose by intramuscular injection. An experiment was made to see whether this phenomenon could be shown in the frog. An inoculation of toxin via the dorsal lymph sac has been shown to be virtually equivalent to an intravenous injection, and so the effect of intramuscularly injected toxin was compared with the effect

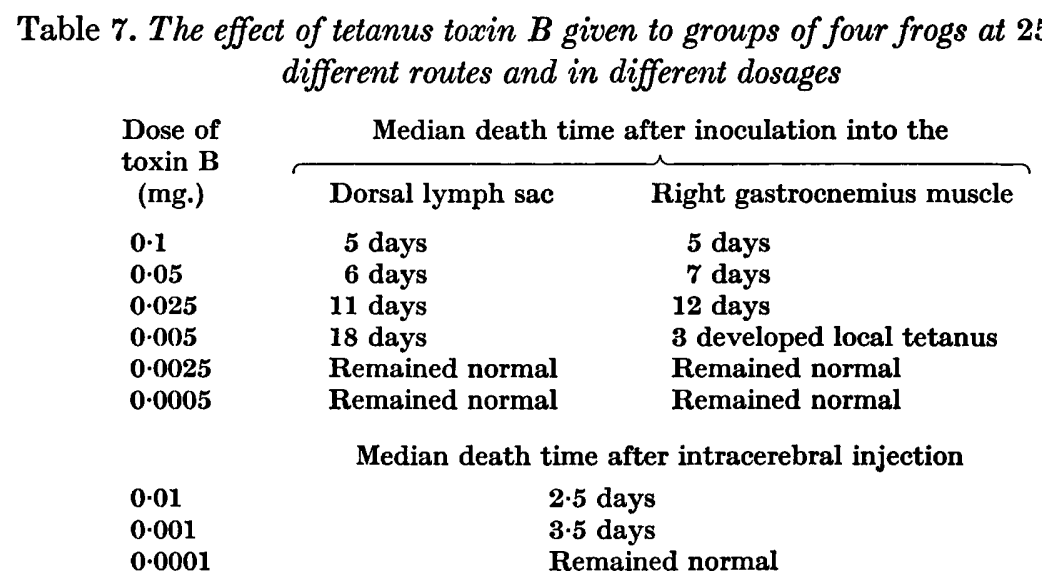

of a similar dose given via the dorsal lymph sac. Two groups of 24 frogs were inoculated with tetanus toxin $\mathbf{B}$, one group intramuscularly in the right gastrocnemius muscle, and the other via the dorsal lymph sac. Each group was divided into six subgroups, which received doses of toxin as shown in Table 7. The volume of toxin solution given to each frog was the same $\left(0.1 \mathrm{ml}\right.$.) and they were all kept at $25^{\circ}$ after inoculation. With $0.025 \mathrm{mg}$. or greater doses of tetanus toxin $\mathbf{B}$ there was no significant difference in the median death time or in the signs of tetanus produced in the two groups; the frogs all died of generalized tetanus. However, with $0.005 \mathrm{mg}$. toxin $B$ three of the four frogs inoculated intramuscularly developed a mild local tetanus in the inoculated limb. They were able to swim but there was a marked reduction of flexion at the knee, and to some extent at the hip, as compared with the normal leg. The opposite leg was not involved and the condition did not progress or regress during the 21 days for which these frogs were observed.

From Table 7 it appears that the minimal lethal dose of tetanus toxin was slightly larger by intramuscular injection than by inoculation via the dorsal lymph sac. This is the reverse of what has been described in mammals and may be due to the toxin 
escaping from frog muscle more quickly than from mammalian muscle because of the greater blood capillary permeability in frogs. This view is supported by the failure to produce local tetanus by intramuscular injection of toxin, when the dose was more than $0.005 \mathrm{mg}$. With a large dose of toxin most of it escapes from the muscle but some passes up the motor nerve. The toxin reaches the central nervous system by two routes and this must be a less lethal process than when all the toxin is injected into the dorsal lymph sac. With a small intramuscular dose of toxin the amount which escapes is not enough to give generalized tetanus and the amount of toxin going up the nerve is only enough to produce a very mild local tetanus.

Intracerebral inoculation. With mammals tetanus toxin has always been found most lethal and dramatic in its action when injected into the central nervous system; this proved to be so with the frogs studied here. Frogs were anaesthetized with ether and $0.01 \mathrm{ml}$. toxin solution injected through the skull into the brain with a 31-gauge needle. From Table 7 it is clear that the dose of toxin required to kill was very much smaller when it was given intracerebrally than by either of the other two routes, and the death time for a given dose of toxin was much shorter. Cooling to $16^{\circ}$ prevented the development of tetanus after an intracerebral injection of toxin. Two groups of three frogs were inoculated intracerebrally with $0.01 \mathrm{mg}$. tetanus toxin $\mathrm{A}$ and kept at $16^{\circ}$. After 6 days no signs of tetanus were observed. One group was then moved to a tank at $25^{\circ}$ where they developed generalized tetanus after $24 \mathrm{hr}$. The second group was moved to the warm tank after 11 days in the cold and then developed tetanus after a further $24 \mathrm{hr}$. Tetanus following the intracerebral inoculation of toxin was very rapid in its progress and a frog which appeared normal in the morning might show gross signs of generalized tetanus in a few hours and die in the evening. In some cases after the intracerebral inoculation of tetanus toxin frogs showed signs of irritability and on being disturbed moved violently around the tank in a quite abnormal manner.

Intraneural inoculation of the sciatic nerve. In mammals the injection of a very small dose of toxin into a motor nerve will produce a severe local tetanus in the muscles supplied by the inoculated nerve. Some experiments were made to produce local tetanus in the frog by this technique. Under ether anaesthesia the sciatic nerve was exposed through a vertical incision in the back of the thigh. A piece of sterile filter paper was placed under the nerve and $0.01 \mathrm{ml}$. solution containing $\mathbf{0 . 2} \mathrm{mg}$. tetanus toxin A was injected with a 31-gauge needle. The frog's sciatic nerve is a very delicate structure and the amount of toxin which remained in the nerve was questionable as a large part appeared to leak onto the filter paper. The incision was closed and the frogs kept in a tank at $26^{\circ}$. In no case did local tetanus develop. A few frogs developed generalized tetanus, no doubt due to toxin which leaked from the nerve entering the general circulation. The intraneural inoculation could not be considered as satisfactory and no conclusions can be drawn from the results.

\section{The production of local tetanus}

It is possible to produce local tetanus consistently in the frog by the intramuscular injection of tetanus toxin. However the dosage is critical and the tetanus mild, for if too much toxin is given generalized tetanus develops as the first sign of intoxication. This is probably due to toxin leaking from the injection site into the general circulation. The local tetanus which follows the intramuscular injection of a suitable dose of 
toxin is so lacking in severity that it may not be recognized and in a group of frogs similarly inoculated only a proportion will show local tetanus. Having observed that a slight local tetanus could be produced by intramuscularly injected toxin it seemed probable that with a larger dose of toxin a more severe local tetanus might be masked by the generalized tetanus which developed from toxin which had leaked into the general circulation. Therefore it was decided to try to neutralize toxin which entered the general circulation by giving tetanus antitoxin via the dorsal lymph sac a few minutes before the intramuscular injection of a large dose of toxin.

Table 8. The effect of intramuscularly injected tetanus toxin in frogs protected by various doses of antitoxin in the general circulation. Similar doses of toxin and antitoxin were given to mice

Dose of tetanus toxin B: $0.2 \mathrm{mg}$. in $0.05 \mathrm{ml}$. saline.

\begin{tabular}{|c|c|c|}
\hline $\begin{array}{l}\text { Dose of } \\
\text { antitoxin } \\
\text { (units) }\end{array}$ & Fate of frogs & Fate of mice \\
\hline 94 & No intoxication & No intoxication \\
\hline 23 & No intoxication & No intoxication \\
\hline 6 & Local tetanus & No intoxication \\
\hline $1 \cdot 5$ & Generalized tetanus & Generalized tetanus \\
\hline 0.4 & Generalized tetanus & Generalized tetanus \\
\hline
\end{tabular}

Five pairs of frogs were given different doses of tetanus antitoxin, as shown in Table 8. Fifteen minutes later they were each inoculated with the same dose of tetanus toxin $\mathrm{B}(0.2 \mathrm{mg} . / 0.05 \mathrm{ml}$. saline) into the right gastrocnemius muscle and put in a tank at $25^{\circ}$. The same quantities of toxin and antitoxin were mixed and injected intravenously into mice to determine whether or not antitoxin was in excess. The frogs which received 94 and 23 units of antitoxin were completely protected. However the pair given 6 units developed a well-marked local tetanus (see Pl. 1, fig. 3). The local tetanus was first apparent on the fifth day after injection of the toxin and did not significantly alter during the next 16 days. The mice which received 6 units of antitoxin survived. The smaller doses of antitoxin which were used did not protect and the mice and the frogs developed generalized tetanus.

In another experiment 10 frogs were given 6 units of tetanus antitoxin into the dorsal lymph sac and $15 \mathrm{~min}$. later they were divided into two groups. One group received each $0.2 \mathrm{mg}$. tetanus toxin $B$ in $0.05 \mathrm{ml}$. of solution intraperitoneally; the other group received the same dose of toxin into the right gastrocnemius muscle. The five frogs given toxin intraperitoneally showed no signs of intoxication during the 21 days for which they were observed, whereas 3 of the 5 frogs inoculated intramuscularly developed a marked local tetanus on the seventh day. Although the local tetanus was moderately severe there was no ascending involvement of the central nervous system and the opposite limb never showed any signs of tetanus.

General anaesthesia with ether abolished the muscular spasm in the affected limb and both legs became equally flaccid. On recovery from the anaesthetic the spasm returned. Two of the frogs with local tetanus were anaesthetized and the sciatic nerve, in the affected limb, cut. This produced a permanently flaccid limb, the spasm of local tetanus not returning on recovery from the anaesthetic. Local tetanus in the frog is therefore dependent, as in mammals, on an intact motor nerve supply and an unanaesthetized central nervous system. 
It was suggested (Wright, 1953) that the force behind the neural transport of substances is the pressure produced inside contracting voluntary muscles. Frogs do not exhibit those frequent movements, typical of mammals. They will sit for long periods completely motionless and it seemed possible that the centripetal neural transport of tetanus toxin might only occur when the intramuscular pressure was raised during active movement. The toxin would therefore pass centrally more slowly in the frog than in mammals and would have a greater opportunity to escape from the muscle into which it had been injected. This would account for the rather poor development of local tetanus in the frog as compared with other laboratory animals.

\section{Table 9. The effect of exercise on the development of tetanus in frogs given} $0.02 \mathrm{mg}$. toxin $B$ and kept at $25^{\circ}$

$\begin{array}{lc}\text { Group } & \begin{array}{c}\text { Day of experiment on } \\ \text { which death occurred }\end{array} \\ \text { Exercise } & 6,6,7,7,7 . \\ \text { No exercise } & 6,7,7,7,8 .\end{array}$

The above hypothesis was tested in two experiments. In the first, 8 frogs were given $0.005 \mathrm{mg}$. tetanus toxin $B$ in $0.05 \mathrm{ml}$. solution, intramuscularly in the right gastrocnemius muscle. They were then divided into two groups; one group was put in a dark tank and not disturbed; the other group was placed in a tank of deep water where they had to keep swimming. Both groups were kept at $25^{\circ}$ and after $24 \mathrm{hr}$. the 8 frogs were put together in one tank. On the eighth day of the experiment the frogs in both groups began to develop local tetanus which did not progress beyond the inoculated limb and was not more severe in one group than the other. In the second experiment a larger dose of tetanus toxin $B$ was used ( $0.02 \mathrm{mg}$. in $0.05 \mathrm{ml}$. solution) and the group of frogs given exercise were kept swimming and hopping for $6 \mathrm{hr}$. before the two groups were put together in one tank at $25^{\circ}$. Again there was no difference between the two groups in survival time and none of the frogs showed local tetanus (Table 9).

The inactivation of tetanus toxin with brain tissue. The excised mammalian brain and spinal cord are capable of combining with large quantities of tetanus toxin; in doing so they inactivate the toxin (see Fildes, 1931, for an account of the WassermannTakaki reaction). The grey matter of the brain is more active than the white matter or the spinal cord in this reaction; no other body tissue shows any comparable neutralizing effect. The brains of birds and cold-blooded animals were found not to neutralize tetanus toxin by Metchnikoff (1898) and it was suggested by Knorr (1897) that their high degree of resistance to tetanus might be connected with the inability of the nervous tissue to combine with the toxin. The fact that many cold-blooded animals are susceptible to tetanus when warmed suggested that either there is a change in the combining power of the brain tissue on warming or that the phenomenon is unconnected with the development of tetanus.

The effect of mixing brain tissue with tetanus toxin was investigated by taking two equal samples of tetanus toxin, each dissolved in $1.0 \mathrm{ml}$. of saline and adding mashed brain tissue to one and an equal volume of saline to the other, which acted as a control. Penicillin (50,000 units) was added to each tube to prevent bacterial growth. After a period of incubation, the amount of free tetanus toxin in each specimen was then determined by inoculating mice intravenously with $0.2 \mathrm{ml}$. of the supernatant 
fluid from each tube. In the first experiment $0.5 \mathrm{~g}$. of brain tissue was placed in contact with $0 \cdot 1 \mathrm{mg}$. tetanus toxin A at room temperature $\left(18^{\circ}\right)$ for $17 \mathrm{hr}$. Under these conditions mouse brain neutralized $90 \%$ of the toxin, whereas with frog brain no neutralization could be demonstrated. Even when tetanus toxin + frog brain were incubated together at $26^{\circ}$ or $37^{\circ}$ no neutralization appeared to take place. The possibility that brain tissue from a frog kept at $26^{\circ}$ for some days would react differently was examined. Three frogs were kept at $26^{\circ}$ for 7 days before their brain tissue was removed and incubated as before with tetanus toxin at $26^{\circ}$. Again no neutralization was observed, although at this temperature the intact animals would have been susceptible to tetanus.

Another theory to explain the failure of frog brain tissue to neutralize tetanus toxin was that some accessory factor, not present in frog brain tissue, is required for the fixation of tetanus toxin. This hypothetical substance might be present in mammalian blood and would be mixed with mammalian brain brei in its preparation. This hypothesis was tested in two experiments. In the first, fresh rabbit serum was mixed with frog brain tissue and the mixture tested as above, no neutralization of tetanus toxin was demonstrated. In the second experiment the possibility that peritoneal fluid might contain the factor was tested by inoculating 3 mice intraperitoneally with a mixture containing 5 mouse LD50 doses of tetanus toxin and $0.5 \mathrm{~g}$. frog brain tissue. These mice developed tetanus and died, showing no increase in survival time as compared with control mice which received toxin only.

\section{The specific precocious protective action of tetanus toxoid}

The specific precocious protective action of tetanus toxoid first reported by Krech (1949) is probably due to toxoid molecules competing with toxin molecules for some receptor substance (Davies \& Wright, 1955). As brain tissue from frogs cannot be induced to neutralize tetanus toxin it must be in some way different from that of mammals. It was therefore of interest to know whether tetanus toxoid would have any protective action in frogs. To demonstrate this phenomenon it is necessary to have a concentrated toxoid preparation; the one used contained $1175 \mathrm{Lf} / \mathrm{ml}$. Seven

Table 10. The protective action of tetanus toxoid in frogs at $\mathbf{2 5}^{\circ}$

\begin{tabular}{ccc}
$\begin{array}{c}\text { Time of toxoid } \\
\text { injection before } \\
\text { the toxin } \\
\text { (hr.) }\end{array}$ & $\begin{array}{c}\text { No. of } \\
\text { frogs }\end{array}$ & $\begin{array}{c}\text { Period of survival after } \\
\text { injection of toxin } \\
\text { (days) }\end{array}$ \\
No toxoid & 7 & $5,6,6,6,6,6,6$. \\
\hline & 4 & $10,12,15,15$. \\
24 & 3 & $11,11,16$.
\end{tabular}

frogs were inoculated with $\mathbf{1 . 0} \mathrm{ml}$. of this concentrated toxoid via the dorsal lymph sac and placed with 7 uninoculated control frogs in a tank at $25^{\circ}$. After $15 \mathrm{~min}$. the 7 controls and 4 of the previously inoculated frogs were each given $0.1 \mathrm{mg}$. tetanus toxin $\mathbf{B}$ via the dorsal lymph sac. On the next day (24 hr. after receiving the tetanus toxoid) the 3 remaining test frogs were given a similar dose of toxin. Table 10 shows the survival time of the three groups of frogs in this experiment. It can be seen that the 
concentrated tetanus toxoid very considerably prolonged the survival time of the frogs but did not prevent the eventual development of tetanus. Tetanus toxoid seems to have the same protective action in the frog as in mammals.

\section{DISCUSSION}

Frogs can be kept at environmental temperatures between $4^{\circ}$ and $28^{\circ}$ but below about $10^{\circ}$ they become noticeably lethargic and at $4^{\circ}$ they remain motionless and only respond sluggishly to external stimuli. Above about $15^{\circ}$ they are sensitive to the action of tetanus toxin but below this temperature they become resistant, although they remain active and respond readily to any disturbance. The change in sensitivity to tetanus toxin comes before there is any noticeable alteration in behaviour and before there is any demonstrable slowing in the rate of absorption of substances injected into the dorsal lymph sac. It seems clear from the experiments on the blood tetanus toxin concentration following its injection into the dorsal lymph sac, that the protective action of cooling is not due to a failure to absorb the toxin into the general circulation. These experiments also demonstrate that the toxin is circulating in an active form and has not been neutralized or toxoided by the frog tissues.

Tetanus toxin produces the same picture of unco-ordinated muscular contraction in the frog as in mammals, and the rate at which the intoxication progresses depends on the dose of toxin. However when using frogs in place of mammals there is an important additional dimension of experimental freedom: the environmental temperature. This might be of value for the analysis of the mode of action of the toxin. Cooling by a few degrees prevents both the fixation of the toxin and its action after fixation but it does not reverse either process. This protective effect of a low environmental temperature must be due either to an alteration in the frog's metabolism or to the toxin being able to act only above a certain temperature. It seems most unlikely that a change in body temperature which does not affect the normal activity of a frog could be accompanied by an alteration in neuromuscular physiology sufficiently profound to give complete resistance to tetanus toxin. It seems more probable that the effect of temperature is on the action of the toxin. Tetanus toxin is a protein and is active at a molecular concentration much below that required for most poisons. This suggests that it may be enzymic in nature and if so, below a certain temperature its combination with substrate and subsequent action might be so slow as to have virtually no effect. If this be true, mammals should also become resistant to tetanus toxin below a certain temperature. There are two reports which suggest that the environmental temperature has some slight effect on the resistance of mammals to tetanus toxin. A seasonal variation in the susceptibility of guinea pigs was reported by Herwick, Weir \& Tatum (1936); they found that the lethal dose of tetanus toxin was $0.006 \mathrm{mg} . /$ $\mathrm{kg}$. body weight in winter and $0.004 \mathrm{mg} . \mathrm{kg}$. in summer. The observations were made over a period of two years and the authors pointed out that any change in the potency of the toxin would probably be a slow deterioration, whereas they found it to retain the same strength at the same season a year later. The increased resistance of these guinea pigs to tetanus toxin in the winter might be due to some cyclic physiological change not directly due to the environmental temperature. Ipsen (1951) observed a similar phenomenon in mice during hot and cold periods and made experiments in which mice were maintained continuously at environmental temperatures of $10^{\circ}, 2^{\circ}$ 
and $35^{\circ}$. Different doses of tetanus toxin were tested and it was found that at $10^{\circ}$ the survival time was generally longer than normal while at $35^{\circ}$ it was shorter. Unfortunately in neither of these two series of experiments do we know the actual body temperature of the animals.

In mammals the site of action of tetanus toxin has been identified as a blocking of inhibitory hyperpolarization of the neurones which control the motor activities of the spinal cord (Brooks, Curtis \& Eccles, 1957). In the frog the following evidence also points to a central site of action: (1) the dose of toxin required to produce generalized tetanus is smaller and the incubation period shorter when given intracerebrally than by other routes; (2) it is difficult to produce local tetanus in the frog by intramuscular injection of toxin, suggesting that it does not act on the nerve endings or muscles; (3) local tetanus is dependent on an intact motor nerve supply, which is at least consistent with the view that the toxin acts centrally.

Although tetanus toxin appears to have the same action in frogs as in mammals, the frog at its most sensitive is about $\mathbf{3 0 0 0}$ times as resistant as a mouse. This might be due to a relatively impermeable blood brain barrier, but the frog is not very susceptible even to intracerebrally injected toxin and the ratio of lethal dose via the dorsal lymph sac to lethal dose intracerebrally is only about ten, a figure smaller than that reported for some mammals (Wright, 1955, p. 440). Therefore the frog's resistance must be due either to an insusceptible brain substance or to the fact that the toxin is operating at a temperature some $10^{\circ}$ lower in the frog than in the mouse. If frogs could be kept at $37^{\circ}$ they would almost certainly be more sensitive to the action of tetanus toxin than at $26^{\circ}$, but probably they would not be as susceptible as mice, for there must be other factors involved. It is relevant that birds, which have a high body temperature, are very resistant to tetanus toxin irrespective of the route by which it is given (Davies, Morgan \& Wright, 1955).

It is not easy to produce local tetanus in frogs. This is probably partly due to toxin being washed from the site of injection by the very great lymph production in the frog's tissues (Isayma, 1924) and partly to the relatively high concentration of toxin required in the central nervous system to produce signs of intoxication. However, when the frogs are partially protected by antitoxin given via the dorsal lymph sac, a moderately severe local tetanus follows intramuscularly injected toxin. Circulating antitoxin will also protect them against a dose of toxin given intraperitoneally, but not against the same dose of toxin intramuscularly. A similar experiment was reported by Friedemann, Zuger \& Hollander (1939) with guinea pigs. They found that when a dose of toxin was given intramuscularly it required between 5 and 8 times as much antitoxin to protect the guinea pigs as would have been necessary had the same dose of toxin been given intravenously. The development of local tetanus in frogs protected against circulating toxin is good evidence for the neural transport of tetanus toxin in the frog. Unfortunately the conclusive experiments involving nerve sclerosis (Baylis, Mackintosh, Morgan \& Wright, 1952) and localized anaesthesia (Wright, Morgan \& Wright, 1952) which have been applied to the rabbit to prove the central site of action of tetanus toxin in local tetanus, cannot for technical reasons be used to elucidate the pathology of local tetanus in the frog.

It has not proved possible to demonstrate any neutralization of tetanus toxin by frog brain tissue, using low concentrations of toxin, and in this frogs may resemble birds. Metchnikoff (1898) was unable to demonstrate the neutralization of tetanus toxin by 
bird brain tissue, but recently van Heyningen (1959a) found chicken brain to be as active as mammalian brain tissue in the absorption of tetanus toxin. The reaction between brain tissue and tetanus toxin is a reversible absorption process (Fulthorpe, 1956), the amount of toxin absorbed depending on the concentration of toxin. Metchnikoff may well have failed to demonstrate absorption of the toxin by bird brain because he used too low a concentration of toxin. The active substance in brain tissue has recently been identified (van Heyningen, 1959 b) as a ganglioside and it seems probable that the combination of the toxin with this substance may be the first step in the action of the toxin. If this be so the high resistance of birds and cold-blooded vertebrates to tetanus toxin might be due to their brain tissue not combining with low concentrations of the toxin.

I wish to thank Professor G. Payling Wright for his help and advice in the preparation of this paper.

\section{REFERENCES}

Baylis, J. H., Mackintosh, J., Morgan, R. S. \& Wright, G. P. (1952). The effect of sclerosis of the nerve trunk on the ascent of tetanus toxin in the sciatic nerve of rabbits and on the development of local tetanus. J. Path. Bact. 64, 33.

Brooks, V. B., CurTis, D. R. \& Eccles, J. C. (1957). The action of tetanus toxin on the inhibition of motoneurones. J. Physiol. 135, 655.

Brunner, C. (1894). Experimentelle und klinische Studien über den Kopftetanus. Beitr. klin. Chir. 12, 523.

Courmont, J. \& Doyon, M. (1893). Du tetanos de la grenouille et des conditions de temperature ambiante nécessaires a son apparition. C.R. Soc. Biol., Paris, 9S, 5, 618.

Cowles, R. B. \& Nelson, N. B. (1947). Studies on thermal sedation in suppression of the symptoms of tetanus toxin. Proc. Soc. exp. Biol., N.Y. 64, 220.

Davies, J. R., Morgan, R. S. \& Wright, E. A. (1955). The susceptibility of pigeons to tetanus toxin. J. Path. Bact. 69, 295.

Davies, J. R. \& Wright, E. A. (1955). The specific precocious protective action of tetanus toxoid. Brit. J. exp. Path. 36, 487.

Frndes, P. (1931). A System of Bacteriology in Relation to Medicine, 3, 339. London: H.M. Stationery Office.

Foxon, G. E. H. \& Rowson, K. E. K. (1956). The fate of Thorotrast (thorium dioxide) injected into the dorsal lymph sac of the frog, Rana temporaria. Quart.J. micr. Sci.97, 47.

FriedemanN, U., Zuger, B. \& Hollander, A. (1939). Investigations on the pathogenesis of tetanus. J. Immunol. 36, 473.

FröHuich, A. \& MeYer, H. H. (1916). Untersuchungen über den Tetanus. Arch. exp. Path. Pharmak. 79, 55.

Fulthorpe, A. J. (1956). Absorption of tetanus toxin by brain tissue. J. Hyg., Camb. 54, 315.

Grasset, E. \& ZUTENDYK, A. (1931). Immunological studies in reptiles and their relation to aspects of immunity in higher animals. Publ. S. Afr. Inst. med. Res. 4, 377.

GuMPrEchT, F. (1895). Versuch über die physiologischen Wirkungen des Tetanusgiftes im Organismus. Arch. ges. Physiol. 59, 105.

Herwick, R. P., Weir, E. P. \& TATUM, A. L. (1936). Seasonal variation in susceptibility of animals to tetanus toxin. Proc. Soc. exp. Biol., N.Y. 35, 256.

IPSEN, J. (1941). Contributions to the Theory of Biological Standardisation, Part III. Copenhagen: Munksgaard.

IPSEN, J. (1951). The effect of environmental temperature on the reaction of mice to tetanus toxin. J. Immunol. 66, 687 .

IsAYma, S. (1924). Über die Geschwindigkeit des Flüssigkeitsaustausches zwischen Blut und Gewebe. Z. Biol. 82, 101. 